\title{
Application of Multimedia Technology in the Course Teaching of Geography of China
}

\author{
Shouye Dong
}

School of History and Geography, Tonghua Normal University, Tonghua, Jilin, China, 134002

66486386@qq.com

Keywords: Multimedia technology; Geography of China; Teaching; Application; Advantage

\begin{abstract}
Geography of China is a highly regional and integrated discipline. Physical geography involves climate, topography, hydrology, soil, and vegetation, while human geography includes population, agriculture, industry, transportation, and city. Good teaching results can hardly be achieved with traditional teaching methods, because the course has limited teaching hours with large and more contents. Traditional teaching methods such as limited class time, massive and large content cannot achieve the superior teaching efficiency. The primary task of instructional method reform of Geography of China is to improve teaching efficiency, this thesis goes through the teaching examples of migration of population, sustainable development of environment in Geography of China, to state the advantage and application skills of multimedia to Geography of China, and conclude that large capacity of multimedia can efficiency solve the contradiction between massive content and limited class time, complete the teaching task well, improve students' learning outcome and ability. At the same time, this thesis offers proposals to notice the problems of using multimedia in class efficiency.
\end{abstract}

\section{Introduction:}

In traditional teaching model, teacher-centered teacher-student interaction teaching system is inefficient, which is unable to keep pace with the speed of the era and students ' thoughts. The learning initiatives of students are significantly inhibited. The class capacity is small, so is the knowledge training volume [1]. It is difficult for students to learn abstract and boring contents. The organization mode of classroom teaching is single. The cognition and abilities of students are not up to standard, and the learning efficiency of geography classroom is very low. As the curriculum system reform of university geography education has deepened in recent years, many problems and defects exist in the teaching of Geography of China, which can not fully meet the requirements of the development of geography education. In this connection, it is of great practical significance to strengthen the reform and construction of the course of Geography of China, enhance the teaching quality of geography teaching, and deepen the reform of geography teaching through deeply analyzing the problems and defects in the teaching of Geography of China. In the reform of teaching methods, the application of multimedia technology in the classroom teaching of Geography of China is becoming increasingly wider. Moreover, good teaching effect can be gained, getting twofold results with half the effort. Thus, this paper combines specific teaching examples to analyze the application prospect and value of multimedia courseware and video in the classroom teaching of Geography of China in terms of Chinese population, environment, and sustainable development.

\section{Course Features of Geography of China}

The subject named Geography of China is one of the compulsory courses and the main courses of Geography Major in normal colleges and universities in China. It is a discipline that studies the relationship between the development process of physical geography, Social-economic process, and spatial laws within specific space in China. It undertakes not only the missions of scientific research 
and application of geography, but also the missions of cultivating professionals of geographical science, propagandizing and educating national conditions, and enhancing the scientific and cultural quality and patriotism of the nation. It also has guiding significance in resources, environment and regional sustainable development [2].

\section{Deficiencies of Traditional Geography Teaching}

An important problem in the teaching of traditional Geography of China is that the teaching way and method is too single. The classroom teaching is that teachers teach students from $\mathrm{A}$ to $\mathrm{Z}$ and students study from A to Z, forming the teaching model of "cramming education". Logic, reasoning, and advancing are attached great importance to in regular order in teaching, which is short of arousing the learning initiatives of students. Geography of China is originally a highly regional and comprehensive discipline. In particular, the relationship between the intuition and practicability of knowledge should be strengthened. If a teacher only narrates factually and unimaginatively in accordance with the knowledge in the textbook, the teaching efficiency will be heavily discounted. For example, in terms of the knowledge about the regional geography, teachers only orally teach the geographical location, natural conditions, economic characteristics, and students only remember the general content. Students don't intuitively feel the teaching contents after listening to the teacher's explanations. They can't form the visual picture of the region in their minds. It is equivalent to learning for nothing. They just obtain the knowledge based on the rigid memory, and they lose the enthusiasm and initiative of study with the lapse of time, which exerts direct impacts on the teaching effects with the loss of the meanings of teaching [3]. If the picture of this region can be demonstrated by this multimedia courseware, the location of the regions, including the size, shape, topography, and geomorphology, giving students strong visual experiences instantly and intuitively. If a teacher presents a picture and plays the video clip of associative zone with explanations at this time, students will have further feelings and analyze geographic area from dynamic perspective. As such, his comprehensive concept and dynamic concept of geographic literacy can be well promoted, formulating deep imprints. The subject features of Geography of China determine the value of multimedia technology to the subject [4].

\section{Advantages of Multimedia Assisted Teaching of Geography of China}

Firstly, the boundedness and hysteretic nature of textbook knowledge can be remedied. In the era of knowledge-driven economy, the boundedness and hysteretic nature of textbook knowledge become increasingly obvious. Geographical teaching has entered the era of multimedia teaching. Geography teachers reach a consensus on multimedia teaching resources, especially through the method of sound, image, picture and video. Geographical video resources can really display natural scenery and human environment, giving people a kind of immersion. The "interesting, useful, and living" geography video information is integrated into geography teaching, making the students feel the aspect of geography. Geography is fresh and interesting, which not only meets the requirements of the new curriculum, but also conforms to communication theory, multiple intelligence theory and constructivism theory. For instance, in terms of the contents of Chinese population migration, if a teacher only narrates the direction, cause of Chinese population migration, it sounds smooth and students only accept the content passively. In lecture, a teacher can play some video materials, like the video clip of Rush to Northeast, "the teacher can propose questions, making students carefully watch and listen to the video in groups; students should use the dialogue in the video to speak out the reasons that Chuanwen and his family rush to the northeast." that is how to introduce the causes for population migration directly. Students are flexible in thinking in classroom with high participation and favorable classroom effects.

Secondly, the diversity of teaching methods is attained. The contents of geography of China are extensive with huge amount of information. The characteristics of multimedia technology and 
network diversity can make up for the defects of manifestation and expression in the teaching contents in the Geography of China textbook. In order to accomplish the dynamic condition and sound effect of geographical elements, the additive method of multi-tier distribution can gradually demonstrate the elements of superposed teaching content of Chinese territory. In this connection, projection, slide, video and multimedia, computer assisted teaching software and other modern teaching means are used for intuitional instruction, improving the students' opinions on geography. For example, as for the section of marine environment in the chapter of ocean, relevant multimedia clips can be displayed. For instance, the thick smoke emitted from chimney stack, constantly chopped trees, mercilessly slaughtered animals, and the discharged sewage into rivers at the start of the film called The Mermaid, reproduce the increasingly harsh living environment again. Although there is no narrator, these pictures of strong visual impacts with bleak and grave music show that the environment on which people live has been threatened by growing crisis with pressed rhythm. The courseware starts with appalling and grand scene to grab students' attentions and improve their learning interests, leading in the new class naturally [5].

Thirdly, the diversification of teaching mode should be attained. Classroom teaching model is one of the most sensitive factors which exert impacts on teaching quality. The shift of teaching mode is bound to improve or lower the quality of class teaching. In recent years, the classroom teaching model has become an important issue for the teaching research of the subject of Geography of China, including many other disciplines, even the entire education sector. In the classroom teaching of Geography of China, we should break the traditional teaching mode and set up a new teaching method system, realizing the diversity of teaching methods. Lecture, assignments, self-study, and practice experience can be applied. The feasibility and specific methods of students' participation in teaching can change the one-way teaching of bidirectional teaching, attaining interactive teaching. In this process, it is intuitive and convenient to adopt multimedia technology, which is also easy to be accepted by students. Therefore, the function and importance of multimedia technology can not be ignored [6].

Fourthly, the geographical knowledge of students should be enriched; the regional concept should be expanded; the enthusiasm for study should be stimulated.

As multimedia technology develops, multimedia technology exerts increasingly obvious impacts on the physical and mental changes of young people. It is difficult to stimulate the learning interests of students just depending on the existing teaching materials, teachers' language, or a small amount of geographic pictures. The classroom resources and teaching contents can be enriched, which can improve or arouse the "interests" of students to learn geography as well as the academic levels and geographic literacy of students.

For example, in terms of the chapter of the development of Chinese population and social development, traditional teaching thoughts makes students know and master the development process and features of Chinese population. Data comparison can be used to make students know and master these contents. In fact, students have mastered the contents of this part when they are in junior and senior high schools. As such, the teaching of Geography of China in university can not just stay at this level. When teachers teach the development process of Chinese population with multimedia in teaching, they can completely make data become curve graph. By doing so, the development process of Chinese population is as plain as daylight. Students can easily comprehend and memorize the growth time and reducing time of Chinese population. The supplement of dynamic video of Chinese population change can make students further analyze the characteristics of Chinese population, development trend and countermeasures. The whole teaching process is natural and smooth with hook-ups, which can also improve the learning initiatives and enthusiasms of students.

Fifthly, the ability to analyze problems from comprehensive and dynamic perspectives should be developed. The rational thinking of interpersonal relationship should establish the concept of sustainable development of "harmony between human and nature"

The relationship between human and land is the main line of the entire geography curriculum and 
the rational thinking of interpersonal relationship. Establishing rich sustainable development idea of "harmony between human and nature" is the eternal theme of geography. In this connection, setting up the correct relationship between people is one of the basic geographical qualities of students.

In the process of "the historical evolution of the thought of the relationship between human and land as well as the sustainable development road, the contents in the textbook are only some boring narratives, expressing the historical stage of the relationship between human and students, the significance, contents, and the principles of sustainable development, as well as the road of pursing sustainable development, which can make students easily become tired of the situation. Students can not truly understand and correctly realize the scientific development concept, and the correct teaching effects can not be achieved. Although the knowledge in this class is not difficult, students can read texts and complete the sustainable development of "rational" learning. However, empty words are not easy for people to profoundly comprehend and utilize. As such, after reading the text, teachers can introduce the video content in A Bite of China, like, in the natural cross-bred forest of pine trees and oak trees, Zhuoma is looking for a kind of sylphlike food ----- tricholoma matsutake. Every Tibetan has eyes for identifying tricholoma matsutake. After tricholoma matsutake is unearthed, Zhuoma covers the hole with pine needles on the ground immediately. Only in this way, hyphae can not be destroyed. In order to continue the gift of nature, Tibetans carefully follow the rules for forests [7].

Multimedia video shows the harmonious co-existence between human, natural environment, and human landscape, as well as the fragile ecological environment of China, having a look at how to strike a balance between human and nature. While students watch the video, teachers can also guide students to talk about the question of facing sustainable development and the measures of achieving sustainable development. Students should analyze perceptual viewing rationally, further deepening interpersonal relationships and establishing correct humane concepts.

In the era of big data, cases in the textbook are far from enough to satisfy the demands of teaching. Geography teachers can obtain a large amount of "nutrition" and rich geographical quality, which can not only stimulate students' interest in learning, but also cultivate the geographic analysis ability of students from the regional, comprehensive, dynamic and ecological perspectives. Furthermore, the regional emotions of students can be improved, setting up the concept of sustainable development between "human and nature".

\section{Suggestions on Applying Multimedia Technology}

Firstly, the design capability of teachers and the quality of multimedia courseware should be improved. At first, teachers should meticulously study the teaching material and carefully consider the syllabus, clarifying the contents of all parts of teaching objectives. As such, we must pay attention to this point. Teachers should selectively choose the most appropriate teaching multimedia form in terms of the teaching basis of the teaching content. Multimedia courseware is difficult to satisfy the law realization of students. Good Multimedia courseware should be compendious and clear [8]. The form should be complex and nonmiscible with moderate knowledge ability and appropriate difficulty. Therefore, the design focus should be put on the teaching about the design. Some time should be given to students for discussion and exploration, making students rethink profoundly, highlighting pupilage, and reflecting the leading roles of teachers. That is how to improve the learning efficiency of students. Secondly, multimedia technology and traditional teaching methods should be combined effectively. Multimedia technology is just a kind of teaching means, and it will never replace the classroom teaching experience and wisdom [9]. In terms of the design of multimedia courseware, based on the teaching contents and the cognitive rules of students, multimedia effects should be used appropriately. Multimedia teaching method can only be used as a complement, and it can not completely replace the traditional teaching mode. For example, as for the multimedia technology in the abstract image, the difficulty of teaching content should be reduced, 
which restricts the cultivation of abstract thinking ability and imagination. The traditional teaching method also has many irreplaceable advantages and accumulates a wealth of classroom teaching experience, which is conducive to the emotional communication between teachers and students. In accordance with the performances of teachers, time should be adjusted in terms of the teaching contents and teaching method, addressing the difficulty of students who can't comprehend knowledge. That is how to ensure the continuity of students' thinking and the development ability of students [10].

\section{Conclusion:}

To sum up, multimedia teaching brings vitality and vigor to the teaching of Geography of China, with its intuitionistic and vivid visual propagation effects. It not only saves teachers plenty of time to write and draw on the blackboard, but also extends the time and space ranges which are not on the textbook. It makes up for the hysteresis quality of textbook and improves students' learning interests, which can cultivate the geographic literacy of students. Meanwhile, traditional teaching also has irreplaceable advantages. As such, teachers should make full use of the advantages of multimedia technology in teaching scientifically and rationally. The complement, mutual learning, and complementation of modern teaching methods and traditional teaching methods should be accomplished. That is how to give full play to the advantages of multimedia teaching and overcome its shortcomings, achieving the best teaching results.

\section{References:}

[1] Q.Q. Chen. Methods of improving geography study efficiency by using multimedia [D]. Shandong Normal University, China 2014.

[2] J.Zhao, C.K Chen. Geography of China [M].Beijing: Higher Education Press, China1999. 449-481.

[3] M.Zhang, Application of Multimedia Technology in Effective Classroom Teaching in Middle-school Geography[J].Journal of China Three Gorges University, 2012(34):223-224.

[4] Y.Wu, Y.W. Han. Effective Integration of Multimedia Teaching and Traditional Teaching in Geography Teaching [J].Educational Front, 2012 (01):123-124.

[5] http://media.people.com.cn/n1/2016/0829/c406899-28674557.html

[6] T.Ye, W.X.Bai, Thoughts on the Application of Multimedia Courseware in Geography Teaching[J].Teaching Reference of Middle School Geography, 2005(10):47.

[7] http://wenku.baidu.com/view/29e5d48fb7360b4c2e3f64a5.html

[8] J.L.Xu, Application of Multimedia Technology in Senior High School Geography Teaching [J].Intelligence, 2011 (34):85.

[9] Y.M.Wang, On the Applications of Multimedia in Geography Teaching [J].Science \& Technology Information, 2009(13):602.

[10]Q.Q. Chen. Methods of improving geography study efficiency by using multimedia [D]. Shandong Normal University, China 2014. 